\title{
A CRIANÇA PROTAGONISTA: \\ propostas de transformação do espaço-tempo escolar em uma escola de Educação Infantil
}

\author{
EL NIÑO PROTAGONISTA: \\ apropuestas de transformación espacio-tiempo escolar
}

\author{
CHILDREN'S PROTAGONISM: \\ proposals of transformation of the school space-time
}

\author{
Luciana Hartmann 1 \\ Luis Eduardo Gasperin ${ }^{2}$
}

\begin{abstract}
RESUMO: Este artigo aborda uma prática de valorização de protagonismo infantil, realizada no âmbito do Projeto de Extensão Partilhas Teatrais, em uma escola de Educação Infantil, da cidade de Uberlândia/MG, na qual diferentes metodologias do ensino do teatro (Drama, Contação de histórias e Performance) foram utilizadas para provocar ações de criação e transformação dos espaçotempo escolares.
\end{abstract}

PALAVRAS-CHAVE: infância, protagonismo infantil, escola, pedagogia do teatro

RESUMEN: En este artículo se aborda una práctica de valorización del protagonismo infantil, realizada en el marco del Proyecto de Extensión "Partilhas Teatrais", en una escuela de Educación Infantil, de la ciudad de Uberlândia / MG, en la cual diferentes metodologías de la enseñanza del teatro (Drama, Narración Oral, Performance) fueron utilizadas para provocar acciones de creación y transformación de los espacios-tiempo escolares.

PALABRAS CLAVE: infancia, protagonismo infantil, pedagogía del teatro, escuela

\begin{abstract}
This article approaches a practice of valorization of children's protagonism, carried out in the scope of the Project "Partilhas Teatrais", in a Uberlândia City/MG Kindergarten, in which different methodologies of theater teaching (Drama, Storytelling and Performance) were used to provoke actions of creation and transformation of school space-time.
\end{abstract}

KEYWORD: child, children's protagonism, theatre pedagogy, school

\footnotetext{
${ }^{1}$ Professora do Departamento de Artes Cênicas e do Programa de Pós-Graduação em Artes Cênicas da UnB, atua também no Programa de Pós-Graduação em Performances Culturais da UFG. Atua no campo da Pedagogia do Teatro e dos Estudos da Performance. Bolsista de Produtividade do CNPq - nível 2. email: luhartm@yahoo.com.br

${ }^{2}$ Professor e encenador independente. Doutorando pela Unicamp, com pesquisa em andamento (previsão de defesa em 2021), na Linha de pesquisa poéticas e linguagens da cena, sob orientação da Prof. Dra. Verônica Fabrini M. Almeida. email: gasperineduardo@hotmail.com
} 


\section{Notas Introdutórias}

Um, dois, três, lá vamos nós! Quatro mãos e vinte dedos, dois corpos para agir e mediar um processo de vivência teatral com crianças pequenas, realizada em fevereiro de 2018. "Tudo era uma brincadeira e foi crescendo" e virou uma frutífera troca em uma escola de educação infantil. Um corpo em Uberlândia-MG e outro corpo em Brasília-DF, surge um convite de união desses dois corpos para um compartilhamento de trajetória, de processos pedagógicos, de ações para e com crianças no AGORA. Comecemos então abrindo um espaço para a singularidade de cada um:

Olá, sou Eduardo - pai do Joaquim. Para as plataformas lato sensu sou Luiz Eduardo Rodrigues Gasperin doutorando em Artes da Cena na UNICAMP. Nas plataformas informais sou apenas Edu. No campo das invencionices teatrais, atuei como professor de educação básica de mamando ao adolescer. No período dessa vivência estava na atuação de professor de teatro na educação infantil no Centro Educacional Maria de Nazaré na cidade de Uberlândia.

Eu sou a Luciana, ou simplesmente Lu, mãe da Luiza e da Nina. Luciana Hartmann, graduada em Artes Cênicas e "doutora" em Antropologia Social. Minhas doutorices se debruçam sobre a arte narrativa, a Contação de histórias com todos aqueles que estejam dispostos a contar e ouvir, de gauchos uruguaios a crianças que imigraram para a França. Desde 2009 sou professora da área de Pedagogia Teatral da Universidade de Brasília.

A partir dessa breve apresentação dos que escrevem, continuemos... Nosso encontro foi em Uberlândia-MG, no âmbito do projeto Partilhas Teatrais em Extensão, que previa a realização de ateliês e redes de aprendizagens teatrais na educação básica. O projeto, coordenado pela professora Paulina Caon, foi realizado em parceria entre o curso de teatro da Universidade Federal de Uberlândia e o Fórum de educadores em teatro do município. O principal objetivo do projeto era promover, através de encontros entre professores de diversas regiões do país, o compartilhamento de práticas teatrais nas redes de ensino público localizadas de Uberlândia.

No nosso caso, o contexto eleito foi um dos territórios institucionais ocupados pelas crianças pequenas. Em uma pequena escola de educação infantil nossas pesquisas se encontrariam para dialogar, na prática, COM as crianças. Delimitado o local, a abordagem escolhida foi de (re)conhecer essa voz que frequentemente é silenciada, a voz das crianças. Ao invés de encararmos a infância como "a idade do não", como critica o sociólogo Manuel Sarmento (2007) 
- não fala, não razão, não trabalho - procuramos valorizar o protagonismo das crianças, olhando, ouvindo, brincando, explorando junto com elas os espaços e tempos da escola.

O planejamento desse encontro ocorreu inicialmente através da internet por meio de e-mails e videoconferências. As ideias foram sendo rabiscadas, garatujas eram feitas e refeitas para compor um desenho que estivesse na altura do nosso "estar juntos" com as crianças. Nas cores e temperaturas de nossos rabiscos, não éramos apenas dois, pois já imprimíamos neles a expectativa do encontro e das trocas com as crianças pequenas e os adultos professores.

Inicialmente no planejamento, e depois, na prática, procuramos sempre pensar nossos corpos adultos em posição de horizontalidade com os corpos crianças, num exercício que Marina Marcondes Machado carinhosamente chama de agachar (2014), ficando mais próximos do chão, do plano baixo, tão raro em nossos cotidianos. Adotamos a noção de protagonismo justamente porque prevê a compreensão de que as crianças são produtoras de cultura (Cohn, 2005), com autonomia e agência na sociedade ${ }^{3}$. Nessa perspectiva, ao invés de simples objeto de políticas e práticas educacionais, a criança se torna co-partícipe em todos os processos que lhe dizem respeito. Helena Singer defende esses aspectos no recente livro "Protagonismo Infantil":

O estudante é o centro de um processo que deverá levá-lo ao desenvolvimento em suas diversas dimensões - intelectual, afetiva, corporal, social, ética. Tal processo tem como ponto de partida e de chegada a autonomia. O sujeito torna-se autônomo quando é capaz de pesquisar e aprender sobre qualquer assunto que lhe interessa, quando se relaciona consigo mesmo e com os próximos de maneira saudável e respeitosa, adota hábitos de autocuidado e vive de forma coerente com seus princípios e valores. (SINGER, 2017: 17)

Com base nesses parâmetros, nossa ação ganhou o título de "A criança protagonista: práticas de transformação no espaço-tempo escolar”. Sentindo necessidade de concretizar o debate, em diálogo com nosso repertório de arte e vida, metodologicamente decidimos combinar elementos da Pedagogia do Teatro

\footnotetext{
${ }^{3}$ Entendemos, no entanto, que o protagonismo não deve se restringir aos estudantes, mas a toda a rede de relações que envolve a comunidade escolar, e o/a educador/a tem um papel fundamental nesse processo. Como defende Helena Singer, "para que o protagonismo do estudante se realize é preciso que seu educador também seja protagonista do próprio trabalho" (2017: 19).
} 
como o Drama (CABRAL, 2006; PAULA, 2016), a Contação de histórias (GIRARDELLO, 2004; HARTMANN, 2016; 2017) e a performance na educação (ICLE, 2013; 2010; PINEAU, 2010; 2013) para propor uma ação que priorizasse o protagonismo das crianças. E para que o protagonismo infantil possa de fato se desenvolver, acreditamos que seja fundamental operar transformações no espaçotempo escolar. A importância de criar condições propícias para a partilha com as crianças é salientada pela antropóloga Constantina Xavier:

Crianças há muito tempo fazem parte de pesquisas em geral; no entanto, nem sempre na condição de sujeitos, sujeitos de direitos, atores/atrizes sociais, colaboradore/as, coautores/as em condições de participação de voz e vez. As crianças têm muito a dizer; para as escutar, porém, é preciso propiciar espaços e condições. (XAVIER, 2014: 16)

E como se consegue gerar essas condições de escuta e partilha? Para responder a essa questão, resolvemos aliar nossa experiência como arteeducadores com a experiência daqueles que convivem diariamente com as crianças: seus professores e professoras.

\section{Pouso no triângulo mineiro}

Nossa "partilha teatral" se deu, in loco, ao longo de uma semana. Primeiro afinamos nossa proposta internamente e logo após realizamos o encontro com o grupo de aproximadamente 15 professores de Educação Básica e arte-educadores da cidade interessados pelo foco de práticas na Educação Infantil. Nesse primeiro momento, apresentamos os caminhos que temos seguido em nossas respectivas pesquisas (Eduardo com o Drama e Luciana com a Contação de histórias e os Estudos da Performance) e fomentamos o debate sobre temas em comum, como a importância de escutar as crianças, de "estar junto" com elas, no mesmo plano, de embarcar em suas histórias e em suas Dramatizações. Fundamentalmente, procuramos demonstrar ao grupo de educadores, através do relato de nossas experiências, como as metodologias ligadas à pedagogia do teatro podem auxiliar nesse processo. Após a troca no âmbito mais teórico, partimos para a prática: propusemos uma série de atividades com os professores, para que se familiarizassem com as dinâmicas que 
costumamos desenvolver com as crianças. Adotando como pano de fundo as memórias e desejos de infância, Luciana partiu de técnicas de Contação de histórias para exercitar a criação narrativa dos educadores e Eduardo partiu do pré-texto de Peter Pan na Terra do Nunca para propor uma pequena vivência dos elementos do Drama. No exercício de olhar para o seu próprio passado, os educadores foram convidados a vivenciar um Drama pocket, no qual puderam compartilhar suas infâncias (lembradas e desejadas), para então (re)pensar as crianças com as quais convivem no presente e melhor compreender suas individualidades e especificidades.

Dois dias depois, com todas as trocas devidamente assimiladas e avaliadas, partimos ao encontro dos nossos protagonistas. Nesse momento, a clareza sobre a importância de adultos e crianças "estarem juntos" e se escutarem foi fundamental. A vivência prática foi realizada com crianças de 5 anos, durante um turno, no Centro Educacional Maria de Nazaré, cidade de Uberlândia-MG. O Centro é uma ONG conveniada e subvencionada pela Prefeitura Municipal de Uberlândia, que atende gratuitamente, em período integral, crianças na faixa etária de 1 ano e onze meses a 5 anos e onze meses.

A turma de crianças já conhecia um dos proponentes, Eduardo, que havia sido seu professor e antes de ocorrer essa proposta levantou seus possíveis interesses. As relações que estabelecemos para realização da prática estiveram aliadas a essas percepções provenientes do contato direto com as subjetividades das crianças. Inspirados em Jean-Luc Nancy, pusemos especial ênfase no sentido da escuta - não apenas como audição, mas como percepção atenta e generosa do outro, uma escuta com o corpo todo - como uma estratégia que propiciasse ações concretas de protagonismo das crianças. De acordo com o filósofo:

O lugar sonoro, o espaço e o lugar - e o ter-lugar -, porquanto sonoridade, não é então um lugar ao qual o sujeito viria para se fazer escutar [entendre] (como a sala de concertos ou o estúdio onde entra o cantor, o instrumentista); é, ao contrário, um lugar que se torna um sujeito na medida em que o som aí ressoa (um pouco, mutatis mutandis, como a conformação arquitetural de uma sala de concertos ou de um estúdio é engendrada em função das necessidades e das expectativas de um projeto acústico). Talvez seja preciso compreender a criança que nasce com seu primeiro grito como sendo ela própria - seu ser ou sua subjetividade - a expansão súbita de uma câmara de eco, de uma nave na qual repercute de uma só vez aquilo que a arranca e aquilo que a chama, pondo em vibração uma coluna de ar, de carne, que soa em suas embocaduras: corpo e alma de um novo qualquer um, singular. Um que vem a si ao se escutar [s'entendant] 
dirigindo a palavra da mesma maneira que ao se escutar [s'entendant] gritar (responder a outro? Chamá-lo?), ou cantar, sempre a cada vez, em cada palavra, gritando ou cantando, exclamando-se como o fez ao vir ao mundo.

Relacionando o lugar com a sonoridade que nele se produzo, o filosofo propõe a compreensão da subjetividade da criança a partir dos primeiros sons que ela produz ao nascer. Grito, choro, que vai se transformando em palavra, canto, história... "Pondo em vibração uma coluna de ar, de carne" a criança tanto se identifica (eu) quanto se relaciona com o mundo (os outros). Acreditamos que no encontro dos corpos adultos com os corpos crianças, faz-se necessário o treino da escuta com todos os poros, uma escuta que evoca todos os outros sentidos, respeitando essas pequenas vozes que buscam suas próprias estratégias para estar no mundo. As comunicações estabelecidas para essa faixa etária nem sempre são diretas, ao contrário, são sutis e necessitam de sensibilidade e cuidado para não serem ignoradas ou mal-interpretadas pelos adultos. Em nossa partilha, procuramos propiciar que as vibrações de som das crianças, que viraram palavras, personagens, risadas, provocassem, por sua vez, sutis transformações no espaço-tempo escolar. Como fizemos isso?

\section{A ação com os pequenos detetives}

Para dar vida ao encontro e concretizar o "estar juntos", priorizando o protagonismo das crianças no processo, partimos de um elemento utilizado no Drama e nos apresentamos às crianças como personagens ou roles: Eduardo personificava o detetive Rintintin ${ }^{4}$ e Luciana a antropóloga Elizabeta ${ }^{5}$. Levamos alguns objetos que nos identificassem, tais como uma Boina na cor preta para o detetive (conquistada em uma de suas viagens pelo mundo) e três penas vermelhas e um par de brincos coloridos em forma de lagarta para a antropóloga (doadas pelos índios à Elizabeta).

\footnotetext{
${ }^{4}$ Inspirado no personagem Tintim, um jovem repórter e viajante belga criado por Georges Prosper Rémi, mais conhecido como Hergé.

${ }^{5}$ Essa inspirada na escritora e ilustradora de livros infantis. polonesa Elzbieta.
} 
Logo depois de nos apresentarmos, convidamos as crianças a ajudarem na resolução de um mistério: por onde andaria a lagarta Kurupeakê? Eles seriam os detetives que buscariam pistas da lagarta. Já os outros adultos (os/as professores/as que participavam da ação) seriam seus ajudantes. Os pequenos detetives escolhiam um adulto para formar pares ou pequenos grupos. Todos tinham nomes inventados - adultos batizavam as crianças e vice-versa - e faziam seus próprios crachás.

Para contextualizar o mistério, Elizabeta/Luciana contou o mito de Kurupeakê $^{6}$, que trata da origem da pintura corporal dos Wayana. Havia um tempo em que Wayana não se pintava... O ambiente ficcional foi desenhado por Elizabeta ao contar da origem das penas que usava. Se tratava de um presente que ganho durante o tempo que viveu entre os indígenas...

O Mito da lagarta Kurupêakê

Certo dia, uma jovem, ao se banhar, viu boiando n'água vários frutos de jenipapo recobertas de figuras. - Ah! Para eu me pintar! - exclamou. Nessa mesma noite um rapaz procurou-a na aldeia até a encontrar. Começaram a namorar e dormiam juntos noite após noite. Entretanto, ao alvorecer, o jovem sempre desaparecia. Uma noite, contudo, o pai da moça rogou-lhe que permanecesse. E ele ficou. Quando clareou perceberam que seu corpo era inteiramente decorado com meandros negros. Como o acharam belo, pediram que ele pintasse a todos, ensinando-lhes essa arte. Um dia, no entanto, o jenipapo acabou. O jovem desconhecido chamou a namorada e foram à procura do fruto. Próximo ao jenipapeiro, o rapaz pediu à moça que o aguardasse, mas ela não obedeceu e foi vê-lo subir na árvore. O que viu entretanto, não foi o rapaz, mas uma imensa lagarta, toda pintada com os mesmos motivos que ele tinha pintados no corpo. Enfurecida, a moça disse-lhe para nunca mais voltar à sua aldeia, pois seus irmãos iriam mata-lo. Ela então juntou os frutos que estavam caídos no chão e regressou, sozinha.

Como temos dito, em nossa proposta a transformação dos mundos escolares está ligada ao incentivo ao desenvolvimento do protagonismo da criança. Para que o protagonismo possa de fato se desenvolver na infância, é importante que a experiência das crianças seja ampliada, que seu repertório seja enriquecido, daí nossa opção pela utilização do Drama e da Contação de histórias

\footnotetext{
${ }^{6}$ O texto é uma adaptação do mito da lagarta "kurupeakê", contado por Aimoré, em resposta a um pedido da antropóloga Lucia Hussak Van Velthen para que lhe contasse sobre a origem da pintura corporal e da decoração da cerâmica dos Wayana. Disponivel em: $<$ http://www.terrabrasileira.com.br/indigena/ornato/724wayana.html >. Acesso em: 20 de julho de 2018.
} 
no processo. Nessa perspectiva, o protagonismo está relacionado à autonomia, experiência e também à imaginação. Como já dizia Vigostki:

Quanto mais a criança vir, ouvir e experimentar, quanto mais aprender a assimilar, quanto mais elementos da realidade a criança tiver à sua disposição na sua experiência, mais importante e produtiva, em circunstâncias semelhantes, será sua atividade imaginativa. (VIGOSTKI, 2014, p. 13)

Os objetos utilizados por Rintintin e Elizabeta, portanto, funcionaram como elementos da realidade que permitiam acessar o mundo o mito, aqui transportado para a escola. E se os objetos acessam o mito, o mito aqui opera como uma porta de entrada para um imaginário comum entre crianças e adultos. A história de Kurupeakê, nesse contexto, é também elemento disparador da troca de saberes e conhecimentos sobre o espaço, sobre a produção dos corpos, sobre nossas subjetividades. Como nos lembra Cristiane Velasco, poeticamente:

O aprendizado não ocorre de forma linear, ele caminha aos saltos. E as histórias nos fazem brincar de balanço, nos auxiliam nesse aprendizado profundo, são nutrientes da alma; a experiência de ouvir uma história pode nos fazer saltar, cada vez mais alto, para dentro de nós mesmos. (VELASCO, 2018: 81)

Saltando para dentro de nós mesmos, depois da narrativa do mito mostramos ao grupo (detetives e seus ajudantes) imagens de pinturas corporais indígenas no computador de Elizabeta. Na sequência, todo o grupo foi orientado a buscar "pistas": desenhos, marcas, registros do lagarto (e de seus possíveis grafismos) no espaço do Centro Educacional Maria de Nazaré - essas "pistas" deveriam ser registradas através de desenhos em folhas de papel que foram distribuídas. No exercício de (re)visitar a estrutura física da escola, com pontos de vista compartilhados entre crianças e adultos, usamos lupas imaginárias que nos permitiram enxergar traços, riscos e formas até então "invisíveis" naquele espaço.

Se, por um lado, praticamente todo o ambiente da escola poderia ser explorado pelo grupo, tínhamos uma limitação de tempo. Como pensar em uma temporalidade fora dos padrões dos ponteiros do relógio? Procurando contemplar a complexidade que essa atividade exigia, propusemos ao grupo aproximadamente 20 minutos para a busca de pistas, mas entendemos que esse tempo poderia ser prorrogado de acordo com a necessidade de cada detetive e 
ajudante. Novamente aqui consideramos que a "escuta" (no caso, dos tempos de cada um) é fundamental. Ao terem de lidar, juntos, com o espaço-tempo escolar, as duplas de detetives e ajudantes puderam viver uma experiência de aproximação e partilha.

Ao retornar à sala, os desenhos foram fixados em um painel, com os adesivos (crachás) que continham seus nomes de detetives. Seguem abaixo alguns registros dessas investigações:

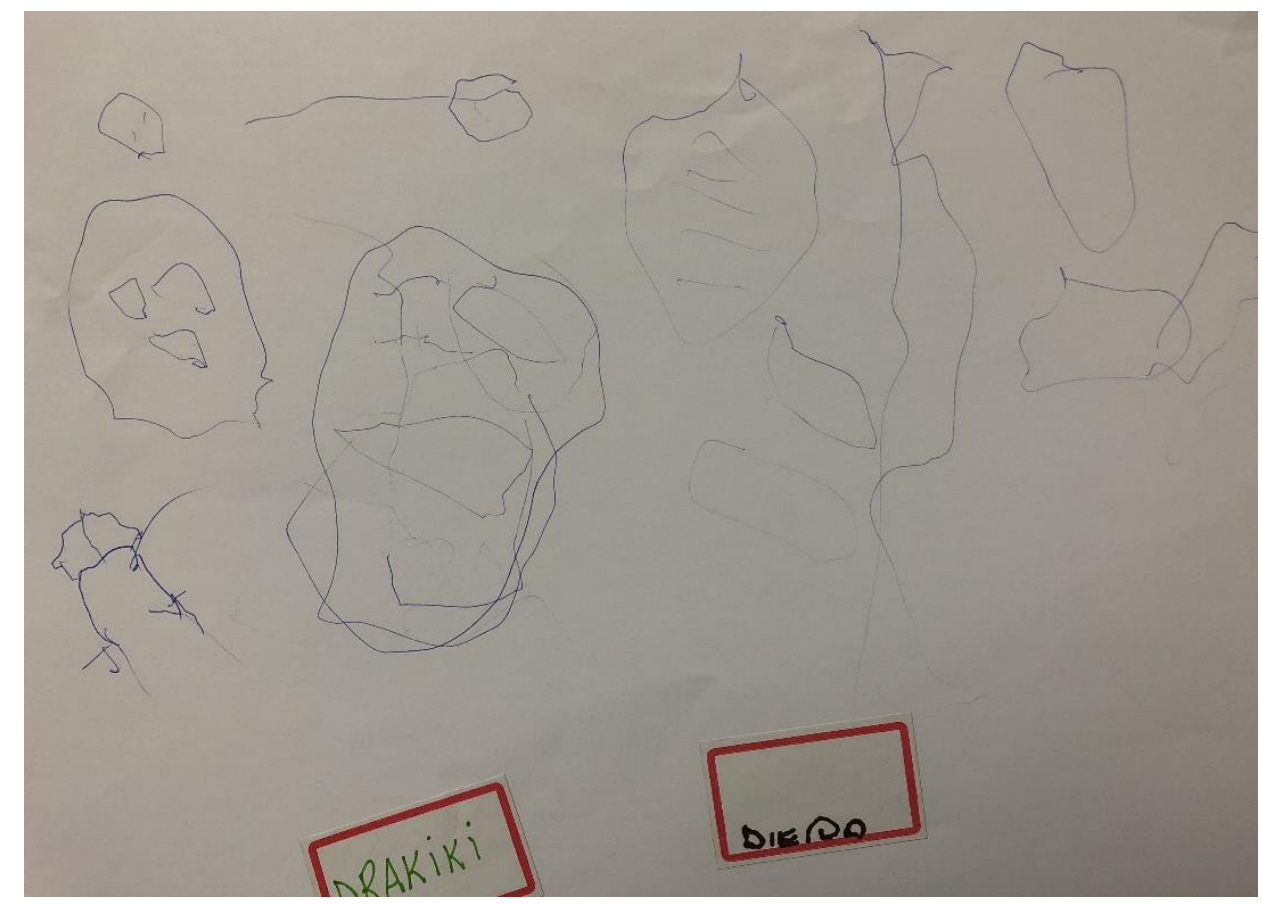



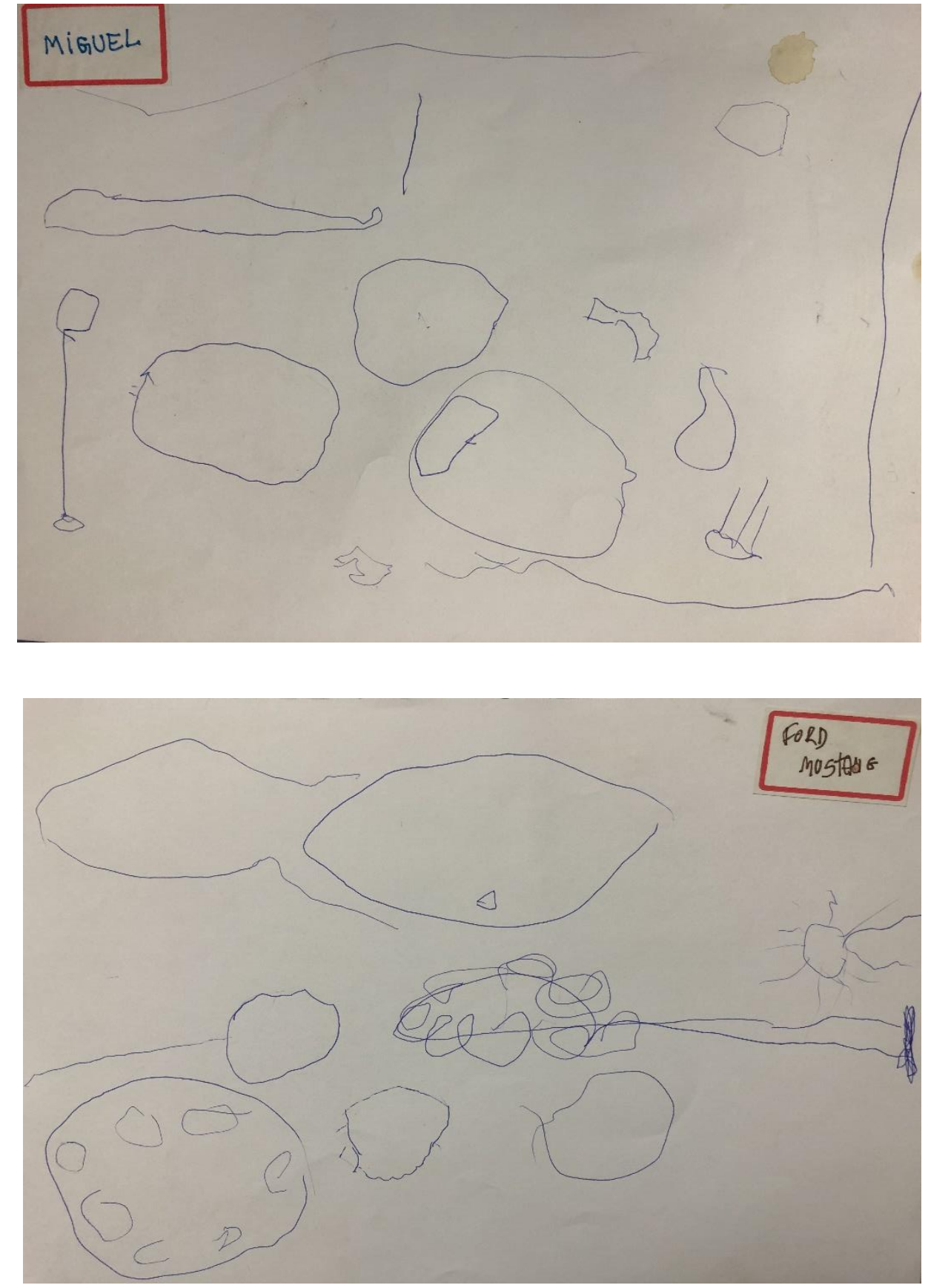

Na explicação de cada registro, de cada pista, de cada traço, o "mistério" foi sendo solucionado coletivamente. Os grafismos das crianças revelavam vestígios da passagem de Kurupeakê pela escola. Muitas crianças comentaram que viram o lagarto andando pelo jardim. Outros optaram por trazer as provas materiais de sua passagem por ali, como uma tampinha, uma folha, uma pedra, cada uma com sua devida explicação. 
Como pudemos perceber, nossa provocação, seja pela narração do mito, seja pelas imagens visualizadas no computador, seja pelo uso dos objetos que decoravam os corpos de Tintin e Elizabeta, afetou os corpos das crianças e dos adultos, gerando novas escutas, novas percepções da escola. Os traços que marcaram no papel revelaram a experiência, compartilhada por crianças e adultos, de (re)conhecer o conhecido.

$\mathrm{Na}$ última etapa da ação, os registros ganham os poros de cada criança e adulto. Rintintin e Elizabeta, prepararam tintas e pincéis, para que o grupo possa experimentar a transposição dos grafismos do papel para o corpo. A orientação, neste caso, foi de que as duplas ou pequenos grupos explorassem todas as lâminas e a partir de seus interesses pudessem vivenciar os traços e formas nos corpos. O material utilizado nesta etapa também era conhecido. Tinta e pincel na educação infantil são materiais recorrentes. Para nossa ação escolhemos as cores preto e vermelho, acrescidas de pitadas de ficção. Contamos que elas tinham origem de frutos da floresta, o vermelho oriundo do urucum e a preta do jenipapo. Com elas, os corpos receberam novas cores e traçados. A pintura aliava, em interferências mútuas, a percepção de diferenças e semelhanças de um corpocriança para um corpo-adulto, e vice-versa, como se pode perceber nas fotos abaixo.
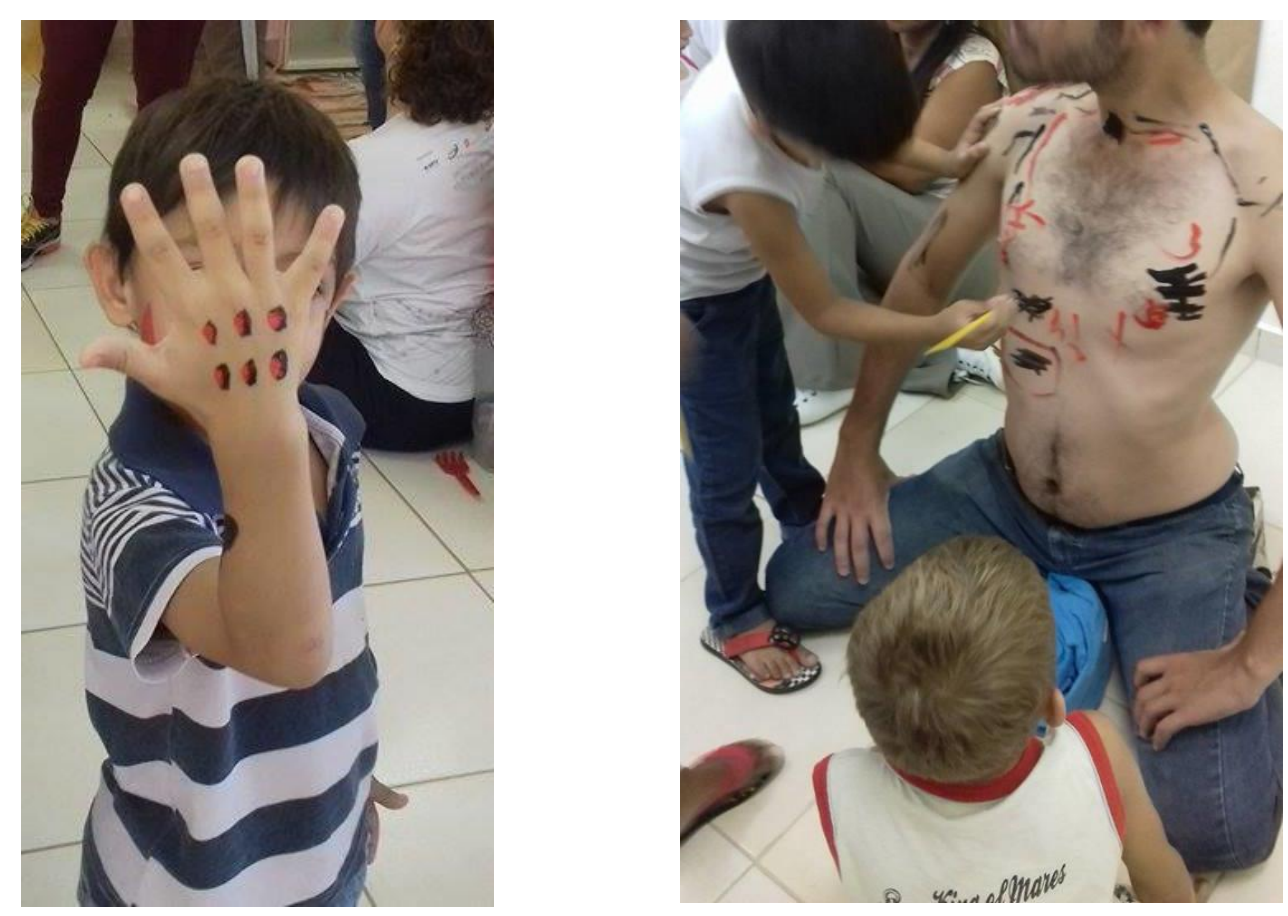


\section{Mistério desvendado?}

A finalização do processo foi dividida em duas etapas, a primeira delas realizada com as crianças e adultos, ou melhor, detetives e ajudantes, e a segunda apenas com os adultos educadores. Na etapa com as crianças, realizada ao final da visita de Rintintim e Elizabeta, trouxemos para a conversa com o grupo, sentados em círculo, no chão (todos no mesmo plano) as questões tratadas no processo. Logo surgiram comentários e discussões sobre o lagarto, sobre como vivem os indígenas brasileiros, como realizam suas pinturas corporais (como algumas pinturas têm curta duração e são feitas com tintas laváveis ou de jenipapo, urucum ou são permanentes, como as tatuagens), como, no mito, um homem vira animal... A escola se tornava cenário da história e as crianças assumiam os personagens principais nela.

Já no segundo e último momento da ação, realizada somente com os educadores, os pontos levantados na discussão estiveram voltados para as metodologias utilizadas, para a viabilidade das atividades propostas em espaços da Educação Infantil, para o trabalho com a ficção e com o imaginário nessa faixa etária, entre outros.

Percebemos, nas falas de adultos e crianças, que a atividade poderia ter muitos desdobramentos. Uma criança, por exemplo, pediu para ver o lagarto pintado no brinco usado por Luciana; algumas crianças encostaram as pinturas entre si e carimbaram os corpos dos colegas; uma criança inventou uma língua imaginária para se comunicar com seu assistente. Entre os adultos, comentamos que poderíamos explorar os padrões já existentes na natureza, nos animais, também avaliamos que teríamos garantido melhor visualização das imagens das pinturas corporais indígenas se elas estivessem impressas e que é fundamental escolher um ambiente propício para contar a história, que permita de fato a sua escuta.

Como expomos no início desse artigo, para "estar juntos" unimos e combinamos nossas práticas e estudos desenvolvidos no campo do ensino do teatro para/com crianças. Cada um de nós apresentou as propostas metodológicas com as quais costuma trabalhar e decidimos não eleger uma ou outra forma, pelo Rascunhos | Uberlândia, MG | v.5 | n.3 | p. 150-168 | dezembro 2018 | ISSN 2358-3703 
contrário, combinamos nossos procedimentos para a criação da ação conjunta. Para isso, reconhecemos a Educação Infantil como um espaço-tempo repleto de saberes e visamos uma prática que propiciasse a troca de conhecimentos entre crianças e adultos. Essa escolha evidencia o caráter educativo da educação infantil e o distancia da herança assistencialista das creches e pré-escolas no país (ANDRADE, 2010).

Lidar com esses saberes a partir de uma situação provocativa, trouxe para o centro da proposta o Drama. Experimentado pela instituição através da parceria com o Subprojeto Teatro PIBID/UFU, coordenado pelo professor Wellington Menegaz de Paula (Tom) que reconhece esse método de ensino pelo viés da exploração e da coletividade:

Se trata de uma investigação teatral, de uma construção coletiva que se dá em processo em que todos os envolvidos estão em jogo, assumindo papéis (roles) e explorando situações propostas pelo coordenador, ou as que surgirem das improvisações. (PAULA, 2016, p.94)

Durante aproximadamente um ano o CEMN foi um campo de proposições do Drama7. Um elemento fundamental para essa abordagem é o pré-texto, sendo ele de origem diversa: histórias, fotografias, imagens, música, reportagem etc. $\mathrm{O}$ pré-texto está diretamente relacionado ao contexto real, somente a partir de uma situação presente ou que estejam em relação com os corpos que vão estar inseridos nele em jogo. São essas características que combinadas com um contexto ficcional, geram uma proposta de Drama Process. Para exemplificar, durante a parceria entre CEMN e PIBID/UFU em 2016, realizamos o processo de Drama que utilizou como pré-texto a história de Alice através do espelho de Lewis Carroll. 8

Para a realização da ação objeto deste artigo, evocamos o contexto investigativo que se manifestou entre crianças nos processos anteriores com o Drama, para estabelecer o papel (role) do detetive Rintintim, seu ofício, sua roupa

\footnotetext{
${ }^{7}$ Durante o ano de 2016, em parceria com o subprojeto teatro PIBID/UFU, recebemos bolsistas de graduação em teatro nas aulas de teatro no CEMN. Elegemos trabalhar com o método do Drama, com o intuito de experienciar com crianças e adultos uma vivência teatral, a partir de três prétextos, todos baseados em narrativas literárias: O menino do dedo verde, de Maurice Druon; As viagens de Gulliver, de Jonathan Swift e Alice através do espelho, de Lewis Carroll.

${ }^{8}$ Esse processo pode ser conhecido no artigo de Gasperin (2017)
} 
e seu modo de trabalho. Para capturar essas informações e desejos das crianças, foi necessário um exercício de escuta do adulto. Desta forma, a ação é construída em colaboração com as crianças. Outro elemento importante é o processo: todo Drama é baseado em uma vivência processual, uma situação que será vivida em etapas. Cada encontro pode ser a abertura de uma porta, um traçado que abre pequenos novos caminhos e bifurcações para resolução de um problema. No caso da nossa ação, foi a busca, por parte dos detetives-crianças e seus respectivos ajudantes-adultos, de pistas e vestígios deixados pelo lagarto Kurupeakê na escola.

O Drama trabalha ainda com a ideia de papeis (roles) que possam ser assumidos pelo professor e/ou crianças. Roles são os papéis que os participantes assumem no Drama. No Drama-processo, todos os envolvidos - estudantes e coordenador/professor - estão em jogo, desenvolvendo diversos papéis. (PAULA, 2016, p.109). No processo desenvolvido trabalhamos com quatro papéis - a antropóloga Elizabeta, que trazia em sua profissão o universo investigativo; o detetive Rintintin, que estava diretamente ligado ao imaginário de mistérios já evocado pelas crianças; e o grupo de detetives e ajudantes, que agiam sob a mediação dos dois principais papeis (Elizabeta e Rintintin), no caso, os "teacherin-role”. Esses papeis, ocupados pelos professores, são descritos por Paula:

Quando o coordenador/professor está vivenciando papéis, durante o Drama, damos o nome de teacher-in-role. Um professor, ao desempenhar um papel (teacher-in-role), tem a possibilidade de acessar caracterizações mais detalhadas. Importa-me aqui destacar a abordagem de Cabral (2008a, p. 42) sobre teacher-in-role: Professor-personagem foi minha tradução para teacher-in-role, [...] decorreu em parte devido à dificuldade de encontrar um termo adequado para "professor-nopapel" (social). Porém dentro do conceito de teacher-in-role estão inseridas as dimensões de representação e presença; Heathcote, por exemplo, interpreta e mantém personagens de outras épocas, lugares, textos, para contrapô-los às atitudes dos alunos, e no mesmo processo de Drama, assume papéis sociais que facilitem sua mediação no jogo. (PAULA, 2016, p.110)

Dessa situação de criar e brincar sobre um ofício (investigação) estamos em exploração de um espaço de convívio e conhecido por eles, transformado para as atividades propostas. Ao realizar essa brincadeira provocamos as crianças e adultos, a perceber e conhecer com outro olhar, outra escuta, outra corporeidade, que interfere nas propostas que eles aos poucos lançam sobre as atividades, na 
escolha de seus nomes, na relação com suas duplas e trios, na escolha dos locais que descobriram as padronagens.

O uso do Drama, nessa experiência, foi combinado com elementos da performance na educação. Entendemos como performance, aqui, o envolvimento integral de todo o grupo (adultos e crianças) em uma relação de troca afetiva, epistemológica, estética. Todos, com seus corpos, suas vozes, sua capacidade imaginativa, seus desejos, seus humores, puderam contribuir para a criação daquele mundo escolar. Contávamos apenas com uma proposta de interação com o ambiente escolar, mas ninguém poderia prever exatamente o que ocorreria. $\mathrm{Na}$ coletividade é que o processo ia se definindo. Como apontam Icle e Bonatto, "A interseção da performance com a educação nos possibilita pensar para além da demarcação de saberes e conhecimentos, exigindo uma forma e organização pautada pela experiência coletiva" (2017:10). Como apontamos na descrição de nossa ação, enfatizando o exercício da escuta com o corpo todo, procuramos valorizar os saberes de cada criança e estimular sua partilha com os adultos.

A indefinição dos processos muitas vezes causa o temor dos professores da "perda de controle" da turma. O risco está dado e o encaramos como constitutivo do processo. Colocar-se em risco significa também estar disponível para encontrar soluções. Na proposta aqui apresentada, a ideia é justamente compartilhar as incertezas e criar soluções conjuntamente com as crianças. Só assim pode se dar o verdadeiro protagonismo, tanto das crianças quanto dos professores. A noção de performance, como lembram os mesmos autores, "possibilita a reflexão sobre alguns aspectos da educação escolarizada e, a partir daí, pode nos levar a experiência diferentes daquelas proporcionadas por práticas tradicionais de ensino, geralmente centradas no professor e pautadas pela interação de transmissão de conhecimento.” (ICLE; BONATTO: 2017, p. 26)

No ambiente escolar, via de regra, os corpos das crianças, "territórios de disputa" do Estado, família, escola, mídia e religião, são treinados e disciplinados por rotinas que regulamentam o tempo, o espaço e os movimentos, determinando "a hora de" e os "locais para" comer, brincar, dormir, estudar, etc. (SILVA, 2012: 217). Em nossa proposta, ao contrário, a ideia foi explorar outros tempos, espaços 
e movimentos possíveis no ambiente escolar. Explorando o tempo de Kurupeakê, enxergamos os grafismos do lagarto pintados nos corpos indígenas. Explorando o espaço da escola, procuramos vestígios desses grafismos. Explorando e interferindo, através das pinturas, nos corpos uns dos outros, sentimos nossas peles sendo decoradas pelos colegas, adultos e crianças.

$\mathrm{Na}$ condução desses processos, é fundamental que sejam eleitas metodologias que permitam, problematizem e reflitam sobre as relações de ensino-aprendizagem. Os educadores precisam ser formados para compreender a contribuição que as crianças podem trazer, concebendo a educação em seus contextos específicos, como processo compartilhado (Barbosa, 2009: 184). Isso demanda dos educadores da educação infantil uma escuta diferenciada sensível e atenta. O lugar de fala da criança necessita ser equalizado com o do adulto, para então agirem enquanto sujeitos culturais e sociais no espaço da creche e da préescola, com respeito as diferenças e diversidades que são destacadas em cada grupo. Como aponta Andrade:

(...) podemos compreender que a dimensão pedagógica da educação infantil reconhece a criança como sujeito cultural, não mais um "vir a ser". Conforme Martins Filho (2005, p.14), o reconhecimento da criança como ator social e cultural possibilita a construção de novos caminhos teóricos e metodológicos na educação infantil, capazes de romper com a visão abstrata ou romântica da infância, descontextualizada de sua inserção social. Isto implica uma proposta pedagógica centrada no desenvolvimento das potencialidades infantis, na valorização das manifestações das crianças e na gradativa conquista de novas aprendizagens. E é ainda nessa dimensão pedagógica que podemos apresentar a função evocada nas últimas décadas, e também presente nos discursos das legislações da educação infantil, ou seja, a função de cuidar e educar. (ANDRADE, 2010, p.153)

No caso de nossa proposta, grande parte dos rabiscos, garatujas, pinturas corporais, as histórias, proposições foram protagonizados pelas crianças. No atravessamento das subjetividades, tempos e espaços escolares podem transformados. Acreditamos que proposições de pensar/sentir/fazer para e com a criança pequena através da Pedagogia do Teatro expande as noções que "nós" adultos temos desses sujeitos e nos ensina a compreendê-lo melhor, em seus próprios termos, em seus próprios sons, em seus próprios traços. Este artigo pretendeu demonstrar que escutar as crianças pode render boas histórias.

$$
* * *
$$




\section{REFERÊNCIAS}

ANDRADE, Lucimary B. P. Educação infantil: discurso, legislação e práticas institucionais São Paulo: Editora UNESP; São Paulo: Cultura Acadêmica, 2010.

CABRAL, Beatriz. Drama como método de ensino. São Paulo: Hucitec: Edições Madacaru, 2006. (Pedagogia do Teatro)

COHN, Clarice. Antropologia da Criança. Rio de Janeiro: Jorge Zahar, 2005.

GIRARDELLO, Gilka. (org.). Baús e Chaves da Narração de Histórias. $2^{a}$. ed. Florianópolis: SESC/SC, 2004.

HARTMANN, L.. Esses contadores tão desconhecidos: as crianças. In: Giuliano Tierno; Letícia Liesenfeld Erdtmann. (Orgs.). Narra-te Cidade - pensamentos sobre a arte de contar histórias hoje. 1ed.São Paulo - SP: A Casa Tombada, 2017, v. 1, p. $85-99$.

HARTMANN, L. Pequenos narradores: experiências metodológicas com crianças contando histórias na sala de aula. In: Luciana Hartmann; Jorge das Graças Veloso. (Orgs.). O Teatro e suas Pedagogias: práticas e reflexões. 1ed.Brasília: Editora da UnB, 2016, v. 1, p. 259-280.

ICLE, G.; BONATTO, M. T. Por uma Pedagogia Performativa: a escola como entrelugar para professores-performers e estudantes-performers. Cadernos CEDES, Campinas, v. 37, n. 101, 2017, p. 7-28.

ICLE, Gilberto. Da performance na educação: perspectiva para a pesquisa e a prática. In: PEREIRA, Marcelo de Andrade (org.). Performance e Educação: (des)territorializações pedagógicas. Santa Maria/RS: Ed. da UFSM, 2013. p. 0922.

Nos cruzamentos entre a performance e a pedagogia: uma revisão prospectiva. Educação \& Realidade. Porto Alegre: n. 35, v. 2, 2010, p. 89-113.

MÜLleR, Fernanda; CARVAlHO, Ana Maria A. (orgs). Teoria e Prática na pesquisa com crianças - diálogos com William Corsaro. São Paulo: Cortez, 2009. 
NANCY, Jean-Luc. À escuta. Tradução de Carlos Eduardo Schmidt Capela e Vinícius Nicastro Honesko. Outra travessia. Florianópolis: n.15, v. 1, 2013, p. 159-172.

NANCY, Jean-Luc. A la escucha. la ed. - Buenos Aires: Amorrortu, 2007.

PAULA, Wellington Menegaz de. Drama-processo e ciberespaço: o ensino do teatro em campo expandido. Doutorado em Teatro - Centro de Artes, Programa de Pós-Graduação em Teatro, Universidade do Estado de Santa Catarina, Florianópolis, 2016.

PINEAU, E. L. Pedagogia crítico-performativa: encarnando a política da educação libertadora. In: PEREIRA, M. (org.). Performance e Educação: (des)territorializações pedagógicas. Santa Maria/RS: Ed. da UFSM, 2013, p. 37 58.

SARMENTO, Manuel Jacinto. Visibilidade social e estudo da infância. In: VASCONCELLOS, V. M. R; SARMENTO, M. J. (orgs). Infância Invisível. Araraquara/SP: Junqueira e Marin, 2007, p. 25-49.

SILVA, Maurício Roberto da. "Exercícios de ser criança." O corpo em movimento na Educação Infantil. In: ARROYO, M.; SILVA, M. R. da (orgs.). Corpo Infância - exercícios tensos de ser criança; por outras pedagogias dos corpos. Petrópolis/RJ: Vozes, 2012, p. 215-239.

SINGER, Helena. Pelo protagonismo de estudantes, educadores e escolas. In: LOVATO, A; YRUla, C. P.; FRANZIM, R. (orgs.). Protagonismo Infantil - a potência de ação da comunidade escolar. São Paulo: Ashoka/Alana, 2017, p. 1421.

VELASCO, Cristine. Histórias de Boca o conto tradicional na educação infantil. São Paulo: editora original, 2018.

VIGOSTKI, L. S. Imaginação e criatividade na infância. São Paulo: Martins Fontes, 2014. 
XAVIER FILHA, Constantina. Ver e 'Desver' o mundo em pesquisas com crianças. Textura, n.32, 2014, p. 45-63.

Recebido em agosto de 2018. Aprovado em outubro de 2018. Publicado em dezembro de 2018. 